\title{
Simulation in cardiothoracic surgery: A paradigm shift in education?
}

\author{
Daniel B. Raemer, PhD
}

In April 2007, a Visioning Simulation in Cardiothoracic Surgery Conference was held at our facility in Cambridge, Massachusetts, under the auspices of the Thoracic Surgery Foundation for Research and Education, to explore ideas about the applicability of simulation in the field. ${ }^{1} \mathrm{~A}$ " 'boot-camp" for demonstrating simulation applied to cardiothoracic surgery trainees was reported in the Journal accompanied by an editorial calling for the reform of education that would include simulation techniques. ${ }^{2,3}$ In March 2008, the report of the Thoracic Surgery Foundation for Research and Education Visioning Conference was published in the Journal, outlining a framework to consider incorporating simulation into a new educational paradigm. That article was accompanied by an "Expert Commentary"' by Richard H. Feins, MD, supporting the concept of integrating simulation in cardiothoracic surgery education and articulating 4 challenges to its success. ${ }^{4}$ These hurdles are to (1) change the model of education from an exclusive apprenticeship to a hybrid that would accommodate learning episodes outside the clinic, (2) retrain educators to effectively use simulation, (3) provide adequate simulator technology for the job, and (4) conduct research to determine whether this technique is truly as effective as it intuitively seems. So, what does simulation offer and where are we with respect to these challenges a little more than a year later? There have been pilot programs, demonstration projects, some new product prototypes, and a modicum of research. I would suggest that although progress seems slow, the current momentum could be accelerated toward a true paradigm shift.

The argument for shifting the educational paradigm toward one that embraces simulation seems strong. Work hour restrictions, increasing patient acuity, shortened length-of-stay, and fewer trainees choosing cardiothoracic surgery as a specialty are well-known problems that beg for modernizing and streamlining the training process. Societal pressure to verify competency of providers in all healthcare domains seeks modalities that are more easily validated and consistently applied. Patient safety concerns and an ethical imperative suggest that the opportunity to practice

\footnotetext{
From the Department of Anaesthesia, Harvard Medical School; Department of Anesthesia, Critical Care, and Pain Medicine, Massachusetts General Hospital, Boston, Mass; Center for Medical Simulation, Cambridge, Mass; and Society for Simulation in Healthcare, Cambridge, Mass.

Received for publication July 23, 2009; accepted for publication July 23, 2009.

Address for reprints: Daniel B. Raemer, PhD, Research and Development Director,

Center for Medical Simulation, 65 Landsdowne St, Cambridge, MA 02139

(E-mail: draemer@partners.org).

J Thorac Cardiovasc Surg 2009;138:1065-6

$0022-5223 / \$ 36.00$

Copyright $₫ 2009$ by The American Association for Thoracic Surgery

doi: $10.1016 / j$.jtcvs.2009.07.056
}

before a trainee does his or her first anastomosis on a real patient's coronaries ought to be embraced. Simulation holds the promise to help solve these problems, and the pilot programs and demonstration projects conducted to date have uniformly supported this notion. But, as Feins pointed out, more needs to be done to take this change to its full potential.

A major shift in the model of learning in any healthcare specialty ultimately will require mandatory adoption. Regulatory bodies, specialty boards, insurance companies, credentialing authorities, and governmental agencies will have to begin to include simulation in their requirements with incentives and mandates. There is evidence throughout healthcare on a global basis that movement in this direction is afoot. Simulation requirements have begun to populate the lists of certification standards in a number of nations for laparoscopic surgeons, anesthesiologists, and interventionalists. The American College of Surgeons, American Society of Anesthesiologists, and Society for Simulation in Healthcare have offered accreditation processes for simulation programs. Various malpractice insurance carriers have begun to offer premium discounts and other incentives for clinicians who engage in simulation-based educational programs. National funding for simulation in Israel, Australia, Canada, and the United Kingdom has appeared within the past year. Legislation before the US Congress (H.R. 855/ S. 616) seeks funding for simulation infrastructure and research. The cardiothoracic surgery leadership must actively support this bill and more like it.

Educational research has long held that adult learners benefit most from a cycle of direct experience, reflection, conceptualization, and an opportunity to experiment. ${ }^{5} \mathrm{Sim}$ ulation naturally provides for this cycle via a simulated experience, guided feedback to foster reflection, the opportunity to conceptualize without concern for ongoing patient care, and the vehicle to experiment again and again. In addition, research on expertise suggests that expert performance does not come from time on task itself, but from deliberate practice. ${ }^{6}$ That is, improvement at any level is only achieved if the learner deliberately attempts to progress, is given highly structured instruction, and receives immediate feedback. Simulation provides the mechanism to institute deliberate practice regimens into the curriculum. ${ }^{7}$ Retraining of educators to take advantage of these principles using simulation requires new curriculum, courses, workshops, and, yes, simulations to be developed and disseminated. The American College of Surgeons, American Society of Anesthesiologists, Simulation in Healthcare, and other specialty groups have begun to develop curriculum, workshops, and faculty development courses. A handful of cardiothoracic surgeons have taken advantage. 
Cardiothoracic surgery as a specialty needs to make a concerted effort to formulate its own plan to press forward in these areas.

There is a wide range of applications for simulation in cardiothoracic surgery training and continuing education. These applications might be categorized as (1) skills training, (2) decision making, (3) crisis management, (4) teamwork, and (5) professionalism. Advancing technology and an identified need have stimulated more realistic and educationally sophisticated simulator equipment. Both polymeric hearts and electromechanically enhanced animal hearts have been developed that allow deliberate practice of cannulation, anastomoses, valvular repair, and cardiopulmonary bypass maneuvers. A technologically savvy generation entering the field generally finds these opportunities appealing. Ever improving and refined technology can be expected in the near future as they become commercialized and widely available. A full-scale cardiopulmonary bypass simulator that produces realistic physiology when actually connected to a cardiopulmonary bypass machine has been commercially developed. In combination with one of the heart models and appropriate clinical equipment and supplies, a portion of a full procedure can be realistically simulated with any portion of a computed tomography surgical team involved. Applications involving surgical decision-making, crisis management, teamwork, and professionalism become quite possible. We have been conducting and improving pilot programs with full teams under the direction of one of our cardiac surgeons for 2 years. ${ }^{8}$

Finally, research to establish that simulation education is effective in cardiothoracic surgery awaits. A few narrowly focused studies in other specialties, such as obstetrics, have begun to show improvement in patient outcome as a direct result of simulation education..$^{9}$ A broad research program to study educational methods in cardiothoracic surgery will take substantial funding and considerable time. Experienced researchers in collaboration with social scientists from education, organizational studies, and psychometrics need to be assembled and put to the task. Given the pressures of reduced work hours, unfilled training slots, and the rush of other specialties to reform education, waiting for the definitive proof of simulation's effectiveness that some will demand seems unwise.

The time has come for the cardiothoracic surgery community to invest in this paradigm shift. The initiative must be taken to change the model from the strict apprenticeship to one where time and resources are allocated for out-of-theclinic experiential learning for trainees. The education of educators for these new techniques should be an organized, validated, and efficient effort and not left to each institution to create its own program. Simulator technology development must come from the cardiothoracic surgery educational imperative and not from technology for technology's sake. The field must decide the appropriate cost-effective balance of centralized simulation facilities and in situ simulation tools to meet its curricular needs. A research strategy to validate the new paradigm's effectiveness should be developed and initiated so that it steers this change rather than delays its implementation. Cardiothoracic surgery has the impetus to lead surgery and healthcare in modernizing its educational paradigm if it takes the reins.

\section{References}

1. Carpenter AJ, Yang SC, Uhlig PN, Colson YL. Envisioning simulation in the future of thoracic surgical education. J Thorac Cardiovasc Surg. 2008;135: 477-84.

2. Hicks GL Jr, Brown JW, Calhoon JH, Merrill WH. You never know unless you try. J Thorac Cardiovasc Surg. 2008;136:814-5.

3. Chitwood WR Jr, Spray TL, Feins RH, Mack MJ. Mission critical: thoracic surgery education reform. J Thorac Cardiovasc Surg. 2008;136:812-3.

4. Feins RH. Expert commentary: cardiothoracic surgical simulation. J Thorac Cardiovasc Surg. 2008;135:485-6.

5. Kolb D. Experiential Learning: Experience as the Source of Learning and Development. New Jersey: Prentice-Hall; 1984.

6. Ericsson KA. Deliberate practice and acquisition of expert performance: a general overview. Acad Emerg Med. 2008;15:988-94

7. Ericsson A, Krampe RT, Tesch-Romer C. The role of deliberate practice in the acquisition of expert performance. Psychol Rev. 1993;100:363-406.

8. Stevens L-M, Cooper J, Raemer D, Schneider R, Frankel A, Berry W, et al. Unitbased teamwork and communication training combining high realism simulation and whole-unit interactive workshop in cardiac surgery. Simul Healthc. 2009;4: 109.

9. Draycott TJ, Crofts JF, Ash JP, Wilson LV, Yard E, Sibanda T, et al. Improving neonatal outcome through practical shoulder dystocia training. Obstet Gynecol. 2008;112:14-20. 